\title{
Permeability Prediction in the South Georgia Rift Basin - Applications to CO2 Storage and Regional Tectonics
}

Olusoga Martins Akintunde ( $\sim$ olusogamartins@gmail.com )

University of South Carolina College of Arts and Sciences https://orcid.org/0000-0001-6711-2988

Camelia C. Knapp

Oklahoma State University Stillwater

James H. Knapp

Oklahoma State University Stillwater

\section{Research Article}

Keywords: CO2 storage, South Georgia Rift (SGR), geohydraulic properties

Posted Date: February 10th, 2021

DOI: https://doi.org/10.21203/rs.3.rs-180571/v1

License: (c) This work is licensed under a Creative Commons Attribution 4.0 International License.

Read Full License 
1 Permeability Prediction in the South Georgia Rift Basin - Applications to $\mathrm{CO}_{2}$ Storage and Regional Tectonics

Olusoga M. Akintunde*, Camelia C. Knapp**, and James H. Knapp**

*Formerly University of South Carolina, Columbia, South Carolina

**Boone Pickens School of Geology, Oklahoma State University

Acknowledgements and Disclaimer

We thank John Shafer, Mike Waddell, Adrian Addison, Duke Brantley, Mark Evans, David

Heffner, Scott Howard, and Bill Clendenin for their contributions to this study. We also thank

Professor Manika Prasad of the Colorado School of Mines in Golden, Colorado, for access to

their Rock Physics Laboratory facilities. The thin sections that we used were provided by Dr.

James Rine of the Weatherford Laboratories. We acknowledge the helpful comments from our anonymous reviewers. This material is based upon work supported by the United States Department of Energy (DOE) under Award Number DE-FE0001965. This paper was prepared as an account of work sponsored by an agency of the United States Government. Neither the United States Government nor any agency thereof, nor any of their employees, make any warranty, express or implied, or assume any legal liability or responsibility for the accuracy, completeness, or usefulness of any information, apparatus, product, or process disclosed, or represents that its use would not infringe privately owned rights. Reference herein to any specific commercial

21 product, process, or service by trade name, trademark, manufacturer, or otherwise does not

22 necessarily constitute or imply its endorsement, recommendation, or favoring by the United

23 States Government or any agency thereof.

\section{Abstract}

The lack of the permeability log data necessary to assess reservoir injectivity as well as aid in the correlation and interpretation of existing porosity and resistivity logs for reservoir quality

27 characterization for potential $\mathrm{CO}_{2}$ storage in the heterogenous and complex South Georgia Rift 
(SGR) basin provides the motivation for this study. The focus was on the Triassic-Jurassic red

29 beds buried, entrenched beneath the Cretaceous-Cenozoic Coastal Plain sediments. Moreover,

the significant cost typically between $\$ 10 \mathrm{M}$ to $\$ 100 \mathrm{M}$ associated with drilling and logging for in

31 situ permeability coupled with the limited resolution of existing core data further makes this

32 work necessary. The purpose is to relate, use the interpretation of the predicted permeability

33 distribution to assess feasibility for safe and long-term $\mathrm{CO}_{2}$ sequestration. This study also intends

34 to establish the impacts of active and passive tectonism that has shaped and/or re-shaped the

35 evolution of the basin on the present-day permeability. A methodology was applied that utilizes

36 the pore space and geohydraulic properties of the reservoir from existing laboratory and well

37 data to produce a newly derived permeability log. It shows a non-uniform distribution with

38 depths possibly due to geologic changes in the confined and heterogeneous red beds. The derived

$39 \quad \log$ displays characteristics consistent with observations from the porosity and resistivity logs.

40 The interpretation of these logs provides evidence for the presence of low permeable, tightly

41 cemented and compacted red beds. We conclude that the low permeability aided by the low

42 resistivity depicted in the red beds suggests increased confining stress and reduced injectivity,

43 and that the uncharacteristically low permeability reflects a deformed basin shaped with episodes

44 of uplift and erosion.

\section{Introduction}

46 Permeability is an important reservoir property that measures the ability of a rock to allow fluid

47 to pass through. It is a function of the pore space and pore connectivity within a rock (Mavko et

48 al., 2003). Its pore space property enables it to have a direct, linear relationship with porosity. A

49 rock with high porosity would typically exhibit high permeability so long as it is characterized

50 by large and uniformly rounded grains. However, poor sorting and presence of fine grain 
51 materials can reduce permeability even if the porosity is high. Porosity is heavily influenced by

52 the rock's pore space and grain size distribution, while permeability is controlled by a

53 combination of these factors as well as by other subsurface or near surface fluid flow properties

54 such as tortuosity, pore shape and pore throats.

55 Permeability as a rock property complements porosity for the purpose of assessing reservoir

56 quality either for fluid injection involving $\mathrm{CO}_{2}$ storage or for oil and gas exploration and

57 development. Its importance to the evaluation of the suitability of the confined and porous red

58 beds formations of the SGR basin for safe and permanent geologic $\mathrm{CO}_{2}$ sequestration makes it of

59 great interest to this study.

60 The SGR basin was formed about 215 - 175 Ma through the breakup of Pangaea and opening of

61 the Atlantic. It is believed to be the largest and probably the most geologically complex

62 Mesozoic graben of the Eastern North American Passive Margin (McBride et al., 1989; and

63 Chowns and Williams, 1983). As shown in Figure 1, it covers an area of about 100,000 km²

64 encompassing South Carolina, Georgia, Alabama, and parts of Florida (Chowns and Williams,

65 1983). The basin fills consist of basalts, diabase sills and red beds. Extrusion of the basalt and

66 intrusion of the diabase sills followed the post rifting events that occurred during the Jurassic

67 (Chowns and Williams, 1983; Ghon, 1983; Ghon et al., 1983; and Olsen et al., 1991). The red

68 beds were formed through sediment deposition that accompanied the formation of the basin in

69 late Triassic. Studies by Heffner et al. (2012), Akintunde et al. (2013a), and McBride et al.

70 (1989) show the SGR basin fills to be overlain by the Cretaceous-Cenozoic sediments.

71 This study focuses on the red beds found in the Norris Lightsey \#1 well, in Northwest Colleton

72 County, South Carolina (Figure 1). The Norris Lightsey \#1 was a wild cat well drilled in the 
73 early 1980s to explore for hydrocarbons. It is also one of the very few wells in Southern South

74 Carolina with significant penetration of the Triassic red beds, covering a depth of about 4,000 m

75 and penetrating over 3,100 m of Triassic red beds. The lithology of the Norris Lightsey red beds

76 consists of fine grained sandstones that are mixed with siltstone, conglomerate and mudstone

77 (Figure 2). Geological characterization of these red beds for optimum reservoir quality

78 assessment for safe and permanent $\mathrm{CO}_{2}$ storage will require the interpretation and correlation of

79 a combination of relevant well logs. Core scale laboratory data are of limited resolution and are

80 characterized by coarse sampling at depth. On the other hand, well logs offer fine spatial

81 sampling and continuity that are absolutely essential for comprehensive and uncompromising

82 assessment of the state and suitability of a target reservoir for $\mathrm{CO}_{2}$ storage. Unlike core scaled

83 data, knowledge of reservoir permeability at in situ conditions is important to dynamic reservoir

84 modeling for better understanding and accurate prediction of the distribution of fluid flow for

85 injection optimization and management. Unfortunately for the study location, there is no log of

86 permeability changes at depth to either assess the suitability of the porous red beds for injectivity

87 or correlate with available porosity and resistivity $\operatorname{logs}$ to aid site characterization. This lack of a

88 permeability log, especially at reservoir depths not sampled by the available core laboratory data

89 (Table 1), provides the motivation for this study.

90 Objectives

91 In evaluating subsurface suitability for $\mathrm{CO}_{2}$ storage in a heterogeneous reservoir such as the

92 confined red beds formations encountered in this study area, three questions are important to the

93 interpretation of permeability. How does the permeability change with depth? What do the

94 observed changes reveal about the state of the reservoir for potential $\mathrm{CO}_{2}$ storage? Do the depth-

95 varying permeability changes exhibit the same behavior as porosities at same depth intervals? A 
permeability log because of its continuity within the subsurface meets the optimum resolution

97 required to better quantify, understand and interpret depth dependent permeability changes as

98 these relate to the above questions. Moreover, laboratory derived core scale porosity and

99 permeability measurements (Table 1) are limited in resolution, while porosity and permeability

100 information from wells logs provide continuous coverage for reservoir quality assessment. Core

101 based laboratory data provides subsurface measurements on the order of inch/cm (core scale)

102 whereas well logs measure up to $\mathrm{m} / \mathrm{km}$ (reservoir scale) with better resolution for subsurface

103 characterization. The primary goal of this study is to predict and provide permeability changes at

104 the well log scale for the purpose of optimum reservoir quality assessment for $\mathrm{CO}_{2}$ storage.

105 The local and regional implications of the depth-dependent permeability changes for safe $\mathrm{CO}_{2}$

106 storage, as this concerns the potential for pore pressure build up, fault reactivation, and induced

107 seismicity, is the second issue of interest. Given the relative proximity of the Norris Lightsey

108 well to the Summerville seismogenic zone of South Carolina, the decision to drill and store $\mathrm{CO}_{2}$

109 will also need to address questions about environmental safety as follows. Could $\mathrm{CO}_{2}$ storage in

110 the confined red beds lead to reservoir overpressure capable of causing leakage or threatening the

111 integrity of the storage reservoirs and overlying seals? How can site-specific permeability

112 conditions curtail or expose the risk of fault reactivation and induced seismicity with injection

113 and storage?

\section{Methodology}

115 The approach utilized involves applications of the modified Kozeny-Carman relation (Gomez, et 116 al., 2010, and Mavko et al., 2003) and the Flow Zone Indicator (FZI) technique developed by

117 Amaefule et al. (1993). The modified Kozeny-Carman relation described below in equation 1 


$$
k=\left(\frac{d_{\text {Mean }}^{2}}{72 \tau^{2}}\right) \frac{\left(\phi-\phi_{p}\right)^{3}}{\left[1-\left(\phi-\phi_{p}\right)\right]^{2}}
$$

121 where $\mathrm{d}_{\text {Mean }}$ is the mean grain size; $\tau$ is tortuosity, $\phi$ is the total porosity and $\phi_{\mathrm{p}}$ is the percolation

122 porosity. These properties can be obtained from laboratory measurements on rock samples.

123 Percolation porosity is the porosity when the pore is disconnected and does not contribute to

124 flow. It is generally between 1 to 3\% (Gomez, et al., 2010, and Mavko et al., 2003). Further

125 discussion on the Kozeny-Carman relation including its derivation can be found in Mavko et al 126 (2003), and Schon, (2011).

127 The FZI as used in this study and previous research by Alam et al. (2011), and Prasad (2003)

128 adapts and extends the Kozeny-Carman relation to enable better characterization of the spatial 129 distribution of permeability in a reservoir characterized by presence of heterogeneities. It allows 130 for an assessment of the petrophysical response and sensitivity to dynamic and depth dependent 131 reservoir changes in a way similar to the applications of geophysical well logs for reservoir 132 characterization. Its relationship to porosity $\phi$ and permeability $k$, which represents the 133 application to this study, can be seen in the below equation 2.

$$
F Z I=\frac{0.0314}{\epsilon} \sqrt{\frac{k}{\phi}}
$$

135 In the above equation, 0.0314 is a constant that accounts for the pore size, tortuosity, pore shape, 136 and the pore throat to pore-body ratio (Prasad, 2003). $\epsilon$ (equation 3 ) is the ratio of the pore 137 volume to grain volume.

$$
\epsilon=\frac{\phi}{1-\phi}
$$


139 Further discussion and derivation of this equation can be found in Schon (2011), Prasad (2003)

140 and Amaefule et al. (1993). The application to a porous reservoir is based on the premise that

141 reservoir units with FZI values within a narrow range belong to one hydraulic unit. The

142 implication of this is that these have similar pore throats and therefore constitute a flow unit. The

143 step-by-step procedure for the implementation of the Kozeny Carman and the FZI technique to

144 predict and provide depth-varying permeability changes in the heterogeneous red beds reservoir 145 are discussed as follows.

1. Development of a porosity-permeability transform for the study area based on the Kozeny-Carman approach.

2. Development of FZI from the core derived laboratory measurements in Table 1 to allow for red beds with similar pore throats to be grouped as a single flow unit.

3. The use of the porosity-permeability relationship in step 1 to convert the porosity from the Norris Lightsey \#1 well to reservoir scale permeability at target depths for potential $\mathrm{CO}_{2}$ injection.

4. Incorporation of the results from step 3 into equation 2 using the computed FZI values from step 2 to produce the permeability log.

In both the Kozeny-Carman and FZI applications for this study, we utilized the existing well data, and the core laboratory measurements for the Norris Lightsey \#1 well and other locations with penetrations of the South Georgia Rift red beds (Table 1). The Norris Lightsey \#1 well has the deepest penetration of the red beds, covering a depth greater than $800 \mathrm{~m}$ below the surface to maintain supercritical $\mathrm{CO}_{2}$ injection (Akintunde et al., 2013a). The variations in the porosity and permeability data from these locations are due to the influence of depositional environments (Akintunde et al., 2013b). In addition, these study locations share similar lithologic composition, 
162 age, geologic history and tectonic setting with red beds recovered from several wells within the

163 basin (Heffner et al., 2012; Chowns and Williams, 1983; Gohn, 1983; and Marine and Siple,

164 1974).

165 Results

166 The permeability-porosity relationships based on linear correlation and the Kozeny-Carman

167 relation are shown in Figure 3. A grain size of $250 \mu \mathrm{m}$ was used based on relevant information

168 from literature review (Mavko et al., 2003, and Gomez et al., 2010), and the subsequent testing

169 and comparison with the direct correlation approach (Figure 3). The Kozeny-Carman porosity-

170 permeability relationship yields a more accurate prediction of permeability from porosity than

171 the linear correlation approach (Figure 3).The Kozeny-Carman relationship takes into account

172 the grain size and tortuosity of the rock, whereas the direct correlation does not account. The FZI

173 adapts and extends the predicted permeability from Kozeny Carman to provide estimates of

174 permeability within definable flow units within the reservoir.

175 The FZI allows for a division of the core-derived porosity and permeability data into flow zone

176 units (Figure 4). It performs this by treating the assigned porosity and permeability contributing

177 to the same flow unit as one FZI value. The consequence of this is that reservoir units with FZI

178 values within a narrow range have similar pore throats and therefore constitute a single hydraulic

179 or flow unit. The distribution of the FZI shows that a large concentration of the data falls within

180 FZI of 0.35 . Plugging this value into equation 2 and substituting the well log derived porosity

181 values into the derived porosity-permeability transform (in Figure 3) allow for the production of

182 the permeability log in Figure 5. The permeability log signatures are consistent with the trends

183 exhibited by the porosity log as should be expected given the contribution from porosity. This 
184 provides a measure of the reliability of the Kozeny-Carman prediction and the computed FZI

185 values that contributed to the production of the permeability log. It also shows that rock's

186 volumetric properties, such as pore space and grain size distribution that are primarily

187 responsible for porosity, do exert control on permeability. It is remarkable to note that while the

188 porosities are high, the permeability values are low. This is significant as it shows that factors

189 responsible for porosity such as pore size and grain size distribution are not the sole and most

190 dominant controls on permeability. Permeability also depend on the rock's geometrical and fluid

191 flow properties, such as tortuosity, pore shape and pore throats, that are of critical importance to

192 reservoir injectivity.

\section{Discussion}

194 The derived permeability log (Figure 5) manifests the following characteristics: (1) uniform and non-uniform distribution with depths (2) noticeable spikes or increases at depth intervals 1395 to

$1961440 \mathrm{~m}, 1438$ to $1445 \mathrm{~m}$, and 1458 to $1465 \mathrm{~m}$, (3) generally low permeability values that are less

197 than $2 \mathrm{mD}$, and (4) vertical distribution which is consistent with the trends of the porosity $\log$.

198 The correlation of the permeability $\log$ with the porosity and resistivity logs allows for easy 199 recognition of the highly resistive and non-porous diabase sills at 1410 to $1424 \mathrm{~m}$. Within the 200 confined and heterogeneous red beds that are both above and below the impermeable diabase 201 sills (Figures 2 and 5), non-uniform permeability distribution are observed. We interpret the 202 permeability variations with depth to be due to geologic changes and the presence of fluids in the 203 red beds. These geologic changes involve key controls on permeability such as sorting, pore 204 shape, pore throats and tortuosity. Analysis of photomicrographs (Figures 6 to 9) of thin sections 205 on red bed cores recovered from the Rizer \#1 Test Borehole in Collenton County, South 206 Carolina, provides evidence for these geologic changes. The Rizer \#1 borehole, drilled in spring 
2012, is within $5 \mathrm{~km}$ to the Norris Lightsey well (Figure 1). The similarities in depositional environment and lithologic composition of the Rizer \#1 well red beds with the Norris Lightsey lacustrine red beds provide the basis for the use of these thin sections. Analysis reveals cemented and lithified red beds with abundant quartz overgrowths and calcite cement (Figures 6 to 9). The exposure to increased compaction and possibly periods of sustained subsidence during sediments deposition has significantly altered reservoir properties responsible for permeability judging by the presence of clasts and small pore sizes and pore throats seen in the thin sections. These photomicrographs also show irregular pore shapes and sizes in the tectonically deformed red beds which may be responsible for the non-uniform distribution of permeability with depths (Figure 5).

The low resistivity in the red bed units is indicative of water or brine saturated red beds. This is because the observed log resistivity values ranging from as low as 0.05 to less than $100 \mathrm{ohm} \mathrm{m}$ fall within the range of known resistivity values for water and saltwater reported in Telford et al., 2001. Chemical analysis conducted by Marine and Siple (1974) on pore water from a Dunbarton well with penetration of the red beds found dissolved solid content of approximately 11,000 $\mathrm{mg} / \mathrm{L}$ that supports the interpretation of brine-saturated red beds. Their study also revealed much higher chloride in the red beds $(6720 \mathrm{mg} / \mathrm{L})$ in comparison with water from the CretaceousCenozoic coastal plain sediments $(1.5 \mathrm{mg} / \mathrm{L})$ and the crystalline metamorphic rock (1260$1400 \mathrm{mg} / \mathrm{L})$. Also, there is no gas in the red beds as this would have caused an increase in resistivity. On the other hand, the overlying and non-porous diabase sills are completely dry. This explains the virtually non-existent permeability and the unusually high resistivity of the sills. The interpretation of a brine saturated reservoir is consistent with the plan for a deep saline $\mathrm{CO}_{2}$ storage system for the South Georgia Rift basin. 
230 The consistency in the observed trends of the porosity and permeability logs provides validation

231 for the reliability of the derived permeability log. Their disproportionate values relative to each

232 other however show that the key controls responsible for both are not mutually identical.

233 Porosity is primarily a function of the pore space in a rock. On the other hand, permeability is a

234 function of the pore space and fluid flow properties of the rock such as tortuosity, pore shape and

235 pore throat that control injectivity. This strengthens the need for a permeability log to

236 supplement and complement the porosity log for comprehensive assessment of the suitability of

237 the SGR red beds for $\mathrm{CO}_{2}$ storage. The correlation with the resistivity log which allows and

238 supports the delineation of the diabase sills and the fully water saturated red beds from the

239 interpretation of the observed permeability distribution also provides an additional, independent

240 verification of the genuineness of the permeability log.

241 The ensuing question from the signatures of the resistivity and permeability logs is what does

242 this mean about the state of the reservoir? The resistivity of a formation based on Archie (1942)

243 varies with porosity depending on the nature and degree of fluid saturation as well as on the

244 rock's cementation and tortuosity. For a fully brine saturated reservoir exhibiting the kind of

245 depth varying porosities shown in Figure 5, the consistently low resistivity also suggests a tightly

246 cemented, compacted rock. This is because the presence of brine (as indicated by the low

247 resistivity) exposes the red beds to chemical dissolution and geochemical reactions that

248 contribute to their cementation and compaction. And with increasing confining stress from burial

249 depths, compaction is further aided. The thin sections (Figures 6 to 9) support the inference for a

250 tightly cemented, compacted rock.

251 The process of compaction or lithification in a reservoir closes pores and/or restricts the

252 interconnectivity between pores that are responsible for permeability (Figures 6 to 9). This 
253 process is further enhanced by exposure to increased confining stress with depths. The effect of

254 increasing confining stress is to reduce or weaken the pore pressure by closing openings in a rock

255 responsible for fluid movement (permeability). The thin sections (Figures 6 to 9) support this

256 view as they show severe degradation in grain size distribution, pore sizes and shapes with

257 increasing depths and net confining stress. Apart from geologic changes in the reservoir, the

258 reservoir response to the permeability log signatures may be stress induced. Burial depth, age,

259 geologic history, and composition are additional factors that influence low permeability. The

260 regional implication of the low permeability is that the South Georgia Rift red beds and possibly

261 the ones encountered in other buried Triassic-Jurassic basins in the Southeastern United States

262 are most likely to be low permeable rocks in view of the similarities in age, geologic history and

263 composition (Akintunde et al., 2013b, Marine, 1974, Marine and Siple, 1974).

264 Applications to $\mathrm{CO}_{2}$ Storage and Regional Tectonics

265 In assessing the implications for $\mathrm{CO}_{2}$ storage, we ask these questions. What does the low

266 permeability mean for reservoir quality determination? How would this affect subsurface

267 suitability for $\mathrm{CO}_{2}$ storage? How would this impact $\mathrm{CO}_{2}$ migration and containment in the red

268 beds? Hydrogeologically, the injection, movement and storage of fluids are most effective in

269 underground formations with high porosity and permeability. The direct consequence for low

270 permeability is a reduction in fluid flow and movement even if the porosity or pore space

271 distribution favors substantial fluid storage. Low permeability would impact the degree and

272 effectiveness of injectivity for $\mathrm{CO}_{2}$ sequestration in the porous formation. Whether or not a

273 reservoir would be viable for long term $\mathrm{CO}_{2}$ storage depends not only on the storage capacity but

274 also on the quality of reservoir injectivity. A preliminary petrophysical investigation by

275 Akintunde et al., 2013 b demonstrates that the confined South Georgia Rift red beds in the Norris 
276 Lightsey do exhibit porous intervals with the potential for substantial $\mathrm{CO}_{2}$ storage capacity that 277 far exceeds the 30 million tons set by the Department of Energy. Also, a preliminary reservoir 278 modeling of $\mathrm{CO}_{2}$ injection in the Norris Lightsey red beds by Brantley et al., 2015 basins

279 demonstrates feasibility for injection of at least 30 million tons of $\mathrm{CO}_{2}$ at a rate of 1 million tons 280 per year for $30 \mathrm{yr}$. The overarching issue for the kind of subsurface distribution depicted by the 281 permeability log in figure 5 is the impact on the degree of reservoir injectivity. The desirability 282 for an effective $\mathrm{CO}_{2}$ storage is to have sufficient injectivity to allow seamless fluid flow, 283 movement, and containment without any fear of reservoir failure should the pore pressure 284 exceeds the reservoir capacity. Conceptually, low permeability suggests reduced injectivity 285 which in turn would impact the effectiveness of fluid flow and movement in the heterogeneous, 286 porous red beds. Ideally, an increase if fluid flow and concentration will increase the pore 287 pressure. The implication of increasing pore pressure with fluid injection is to counteract the 288 effect of increased confining stress thereby opening pores and interconnectivity that could 289 enhance permeability or fluid movement. Unless the pre-injection permeability can be physically 290 or geo-mechanically enhanced, the predictably low injectivity will not be promising for effective 291 fluid flow and storage.

292 Low permeability may help with safety and security of storage since the chances of sudden and 293 unsafe pore pressure build up capable of either triggering induced seismicity or threatening the 294 caprock integrity are unlikely with low injectivity. We understand from Zoback and Gorelick 295 (2012) that increasing pore pressure with $\mathrm{CO}_{2}$ especially in the vicinity of preexisting potentially 296 active faults and considering the critically stressed nature of the crust were likely to increase the 297 potentials for earthquake triggering. It is also inferred from Brantley et al., 2016 that the presence 298 of an active fault with a permeability as low as $1 \mathrm{mD}$ can cause significant $\mathrm{CO}_{2}$ leakage. With a 
properly planned injection that incorporates and implements the applicable geological framework as well as robust monitoring and management techniques, the risks of faulting and induced seismicity can be mitigated. A study by Talwani et al. (2007) showing related seimogenic permeability values that are unlikely to cause induced seismicity with fluid injection also lends credence to the potential for safe storage in the low permeable SGR red beds. Ideally, $\mathrm{CO}_{2}$ injection will increase the pore pressure leading to opening of closed pores. So long as this effectively balances the effect of increasing confining stress with depths and does not alter the differential stress equilibrium, the chances of unsafe seismicity within and around the injection reservoir are very unlikely. Moreover, the confining nature of the red beds together with the presence of the impermeable diabase caprocks would ensure containment of the injected $\mathrm{CO}_{2}$.

With adequate pore pressure monitoring before, during, and after injection, the risks to safe $\mathrm{CO}_{2}$ storage may be quickly detected and averted. 4D seismic monitoring can help with understanding and quantifying dynamic reservoir changes to assess storage efficiency as well as the integrity of the overlying cap rocks. The current permeability log would provide the baseline information necessary for the next steps involving reservoir modeling and simulations, seismic modeling, and imaging, as well as field testing to assess the impacts of enhanced permeability on long term storage, the integrity of the overlying diabase sills, and monitor the efficiency and safety of injection and storage.

In terms of the application to regional tectonics, the predicted low permeability at depth reflects a compacted, deformed basin with a history of uplift and erosion. The thin sections' analysis on recovered red beds from the Rizer \#1 Test Borehole in Collenton County, South Carolina (figures 6 to 9) supports this observation. The interpretation of these photomicrographs reveals the presence of red beds whose physical properties including key controls on permeability such 
322 as sorting, pore shape, pore throats and tortuosity have been altered, impacted by tectonically

323 induced post depositional processes (such as compaction and uplift) that have re-shaped the

324 tectonic evolution of the SGR basin following the major phase of rifting. Whether or not the

325 permeability can be recovered and/or enhanced by a physical or geo-mechanical means is

326 beyond the scope of this current research.

\section{Conclusions}

328 The decision to drill and store $\mathrm{CO}_{2}$ will depend on the quality of the reservoir and the safety of

329 injection and containment. Of importance to reservoir quality are the in-situ porosity and

330 permeability that determine the storage capacity and injectivity. Knowledge of the permeability

331 regime is an extremely valuable rock property that dictates and determines the progress and

332 efficiency of injection and storage. Its correlation and interpretation with porosity and resistivity

$333 \log$ s to better understand and characterize the state of the red beds reservoir for $\mathrm{CO}_{2}$ storage

334 provides the motivation for this study. Permeability is most relevant for correlation with these

$335 \operatorname{logs}$, because of its strong connection to fluid saturation, grain size, pore shapes, cementation and

336 tortuosity that are key controls on porosity and resistivity. Core based laboratory data do not

337 have the resolution, scale, and continuity required for correlation and interpretation with well

338 logs. Consequently, a significant, new contribution from this work is the development of a

339 permeability log for the study area based on a robust methodology involving applications of the

340 Kozeny-Carman relation and the Flow Zone Indicator technique. The rationale for the use of

341 these two approaches was to ensure reliable permeability prediction and distribution that

342 considers the pore space and geometrical properties of the target red beds. The development of

343 this permeability log offers an alternative way to save time and significant cost associated with

344 expensive well drilling and logging for in situ permeability measurements for reservoir 
345 characterization. It would also aid dynamic reservoir modeling of the distribution of fluid flow to

346 better characterize the $\mathrm{CO}_{2}$ injection distribution and efficiency for the purpose of storage

347 optimization and management.

348 The interpretation of the permeability log supported by the correlation with the porosity and

349 resistivity logs shows non-uniform distribution with depths possibly caused by geological and

350 stress induced changes in the heterogeneous red beds. Moreover, the petrophysical responses in

351 both the resistivity and permeability logs are generally low. We interpret this in conjunction with

352 the porosity distribution to suggest: (1) the South Georgia Rift is a tightly cemented and

353 compacted reservoir, and (2) a reservoir exposed to increased confining stress. Increasing

354 confining stress closes and/or restricts reservoir openings responsible for porosity and

355 permeability. On the other hand, increasing pore pressure with $\mathrm{CO}_{2}$ injection has the potential to

356 counteract the effects of increased confining stress by opening closed pores or enhancing weak

357 pores for efficient fluid movement and storage over time. However, low permeability will reduce

358 injectivity that is a key requirement for the efficiency of $\mathrm{CO}_{2}$ injection and storage. We also

359 conclude that the predicted low permeability distribution with depth is a function of the active

360 and passive post-tectonic depositional processes that have impacted the physical properties of the

361 Triassic red beds.

\section{References Cited}

363 Akintunde, O.M., C.C. Knapp, J.H. Knapp, and D.M. Heffner, 2013a, New constraints on buried 364 Triassic basins and regional implications for subsurface $\mathrm{CO}_{2}$ storage from the SeisData6 seismic 365 profile across the Southeast Georgia coastal plain: Environmental Geosciences, v.20, p. 17-29.

366 Akintunde O.M., C.C. Knapp, and J.H. Knapp, 2013b, Petrophysical characterization of the 367 South Georgia Rift basin for supercritical $\mathrm{CO}_{2}$ storage: a preliminary assessment: Environmental 368 Earth Science v. 70, p. 2971-2985. 
Alam, M.M., I.L. Fabricius, and M. Prasad, 2011, Permeability prediction in chalks: American Association of Petroleum Geologists Bulletin, v. 95, p.1991-2014.

Amaefule, J.O., M, Altunbay, D, Tiab, D.G. Kersey, and D.K. Keelan, 1993, Enhanced reservoir description: Using core and log data to identify hydraulic (flow) units and predict permeability in uncored intervals/wells: Society of Petroleum Engineers Paper v. 26436, p. 1-16.

Archie, G.E., 1942, The electrical resistivity log as an aid in determining some reservoir characteristics : Transactions of the American Institute of Mining, Metallurgical, and Petroleum Engineers, v.146, p. 54-62.

Brantley, D., M. Waddell, J. Shafer and V. Lakshmi, 2016, Inclusion of Faults in 3-D Numerical Simulation of Carbon Dioxide Injection into the South Georgia Rift Basin, South Carolina: International Journal of Earth Science and Geophysics, v. 2, p. 1-11

Brantley, D., J. Shafer and V. Lakshmi, 2015, $\mathrm{CO}_{2}$ injection simulation into the South Georgia Rift Basin for geologic storage: A preliminary assessment: Environmental Geosciences, v. 22, pp. 1-18

Chowns, T. M., and C. T. Williams, 1983, Pre-Cretaceous rocks beneath the Georgia coastal plain: Regional implications, in G. S. Gohn, ed., Studies related to the Charleston, South Carolina, earthquake of 1886: Tectonics and seismicity: U.S. Geological Survey Professional Paper 1313, p. L1-L42.

Gohn, G. S., 1983, Geology of the basement rocks near Charleston, South Carolina: Data from detrical rock fragments in lower Mesozoic(?) rocks in Clubhouse Crossroads test hole \#3, in G. S. Gohn, ed., Studies related to the Charleston, South Carolina, earthquake of 1886: Tectonics and seismicity: U.S. Geological Survey Professional Paper 1313, p. E1-E22.

Gohn, G. S., B. B. Houser, and R. R. Schneider, 1983, Geology of the lower Mesozoic(?) sedimentary rocks in Clubhouse Crossroads test hole \#3 near Charleston, South Carolina, in G. S. Gohn, ed., Studies related to the Charleston, South Carolina, earthquake of 1886: Tectonics and seismicity: U.S. Geological Survey Professional Paper 1313, p. D1-D17.

Gomez, T.C., J. Dvorkin, and T. Vanorio, 2010, Laboratory measurements of porosity, permeability, resistivity, and velocity on Fontainebleau sandstones: Geophysics, v. 75, p. E191E204.

Heffner, D.M., J.H. Knapp, J.H. O.M. Akintunde, and C.C. Knapp, 2012, Preserved extent of Jurassic flood basalt in the South Georgia Rift: A new interpretation of the J horizon: Geology, v.40, p. 167-170.

Marine, W., 1974, Geohydrology of buried Triassic basin at Savannah River Plant, South Carolina: American Association of Petroleum Geologists Bulletin, v.58, p. 1825-1837. 
Marine W., and G.E. Siple, 1974, Buried Triassic basin in the central Savannah River area: Journal of Geological Society of American Bulleting. v. 85, p. 311-320.

Mavko, G., T. Mukerji, and J. Dvorkin, 2003, The Rock Physics Handbook - Tools for seismic analysis in porous media: Cambridge, Cambridge University Press, 329 p.

McBride, J.H., K.D. Nelson, and L.D. Brown, 1989, Evidence and implications of an extensive early Mesozoic rift basin and basalt/diabase sequence beneath the southeast coastal plain: Geological Society of America Bulletin, v. 101, p. 512-520.

Olsen, P.E., A.J. Froelich, D.L. Daniels, J.P. Smooth, and J.W. Gore, 1991, Rift basins of early Mesozoic age: Geology of the Carolinas, Carolina Geological Society 50th Anniversary, Volume, Ed Horton, p. W 142-170.

Prasad, M, 2003, Velocity-permeability relations within hydraulic units: Geophysics v. 68, p.108-117.

Schon, J.H., 2011, Physical Properties of Rocks: Amsterdam, Elsevier, 350 p.

Talwani, P., L. Chen, and K. Gahalaut, 2007, Seismogenic Permeability, ks: Journal of Geophysical Research 112, B07309, doi:10.1029/2006JB004665.

Telford, W.M., L.P. Geldart, and R.E. Sheriff, 2001, Applied Geophysics: Cambridge, Cambridge University Press, $770 \mathrm{p}$.

Weatherford Laboratories Reports, 2014, Geologic Characterization of the South Georgia Rift basin for source proximal $\mathrm{CO} 2$ storage based on analysis of samples from Rizer \#1 test borehole Colleton County, South Carolina, and the United States Geological Survey Clubhouse Crossroads test hole no. 3, Dorchester County, South Carolina, 149 p.

Zoback, M.D., and S.M. Gorelick, 2012, Earthquake triggering and large-scale geologic storage of carbon dioxide: Proceedings of the National Academy of Sciences of the United States of America, v. 109, p. 10164-10168. 


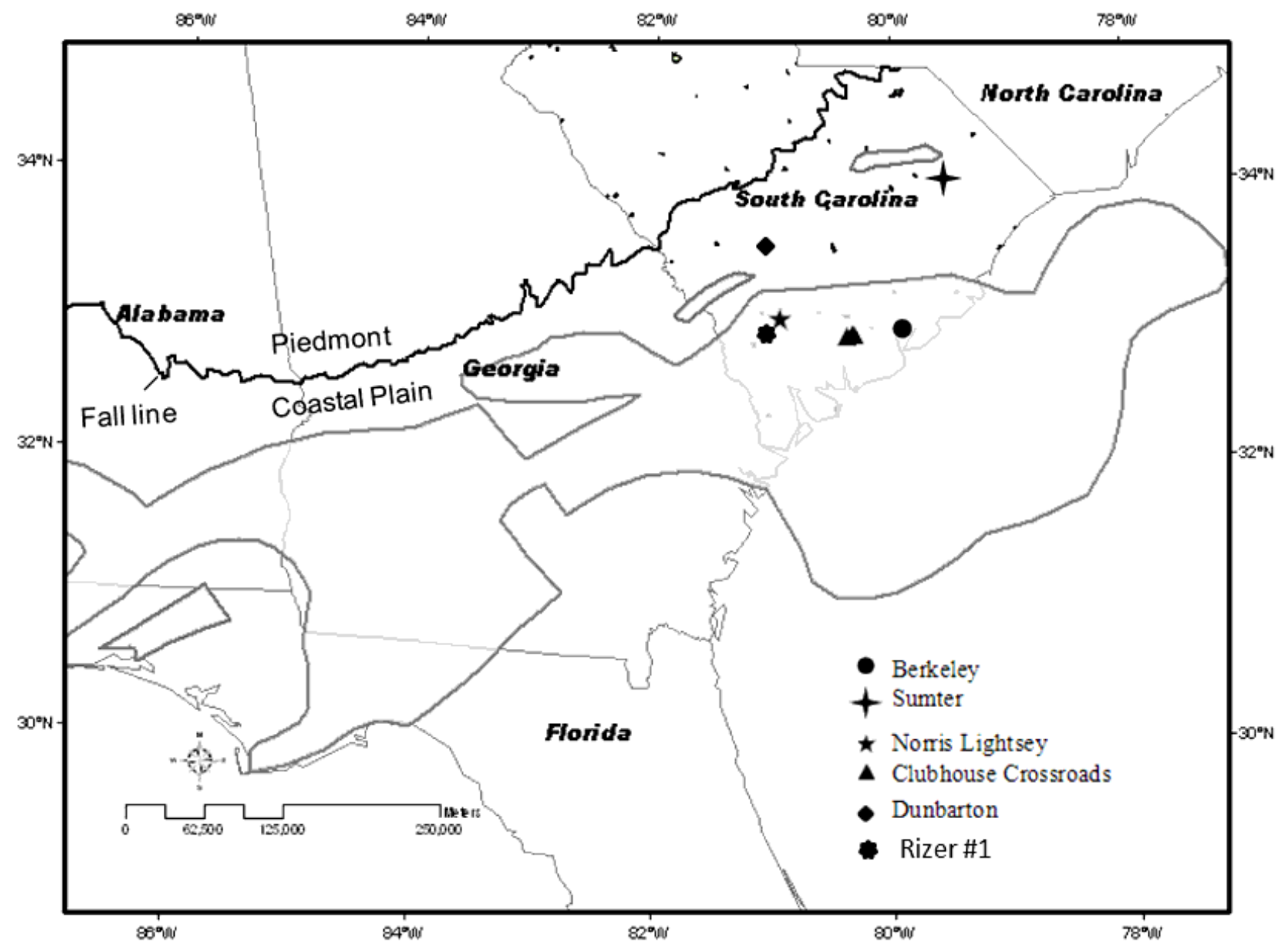

Figure 1

Areal extent of the South Georgia Rift basin (modified from Chowns and Williams, 1983) showing the Norris Lightsey \#1 well study location. Other wells used in this study such as Sumter, Berkeley, Clubhouse Crossroad, Dunbarton and newly drilled Rizer \#1 are shown. Gray shaded area represents the areal extent of the basin 

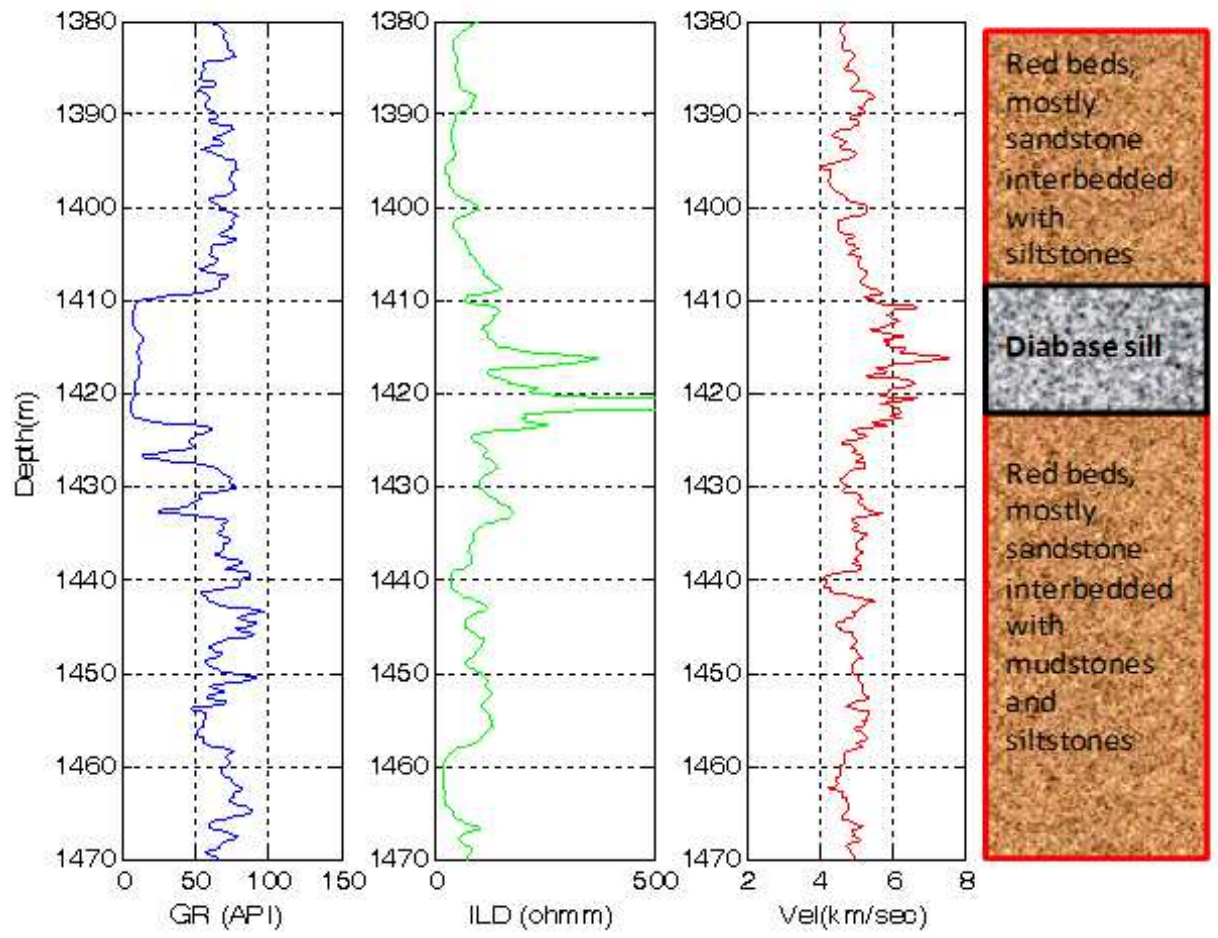

Figure 2

Target reservoir depths from the Norris Lightsey \#1 well for potential CO2 storage. The diabase sill stands out from the red beds by its low Gamma Ray (GR in API), high resistivity (deep induction resistivity log, ILD, in ohm-meter), and high velocity $(\mathrm{km} / \mathrm{s})$ 


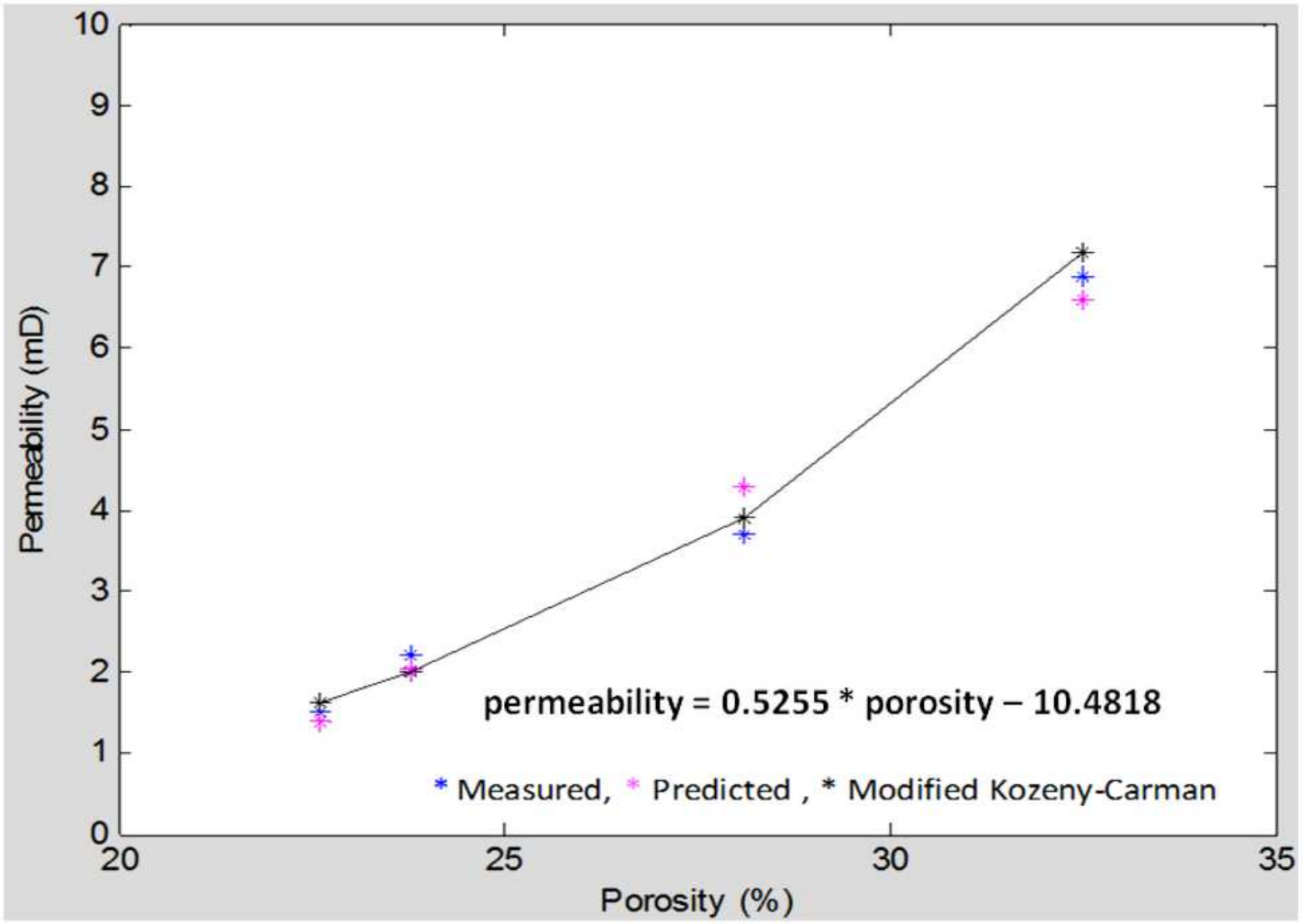

Figure 3

Permeability versus Porosity for the Norris Lightsey \#1 well data shown in Table 1. Prediction by KozenyCarman relation provided the most reliable fit for the plotted data points.
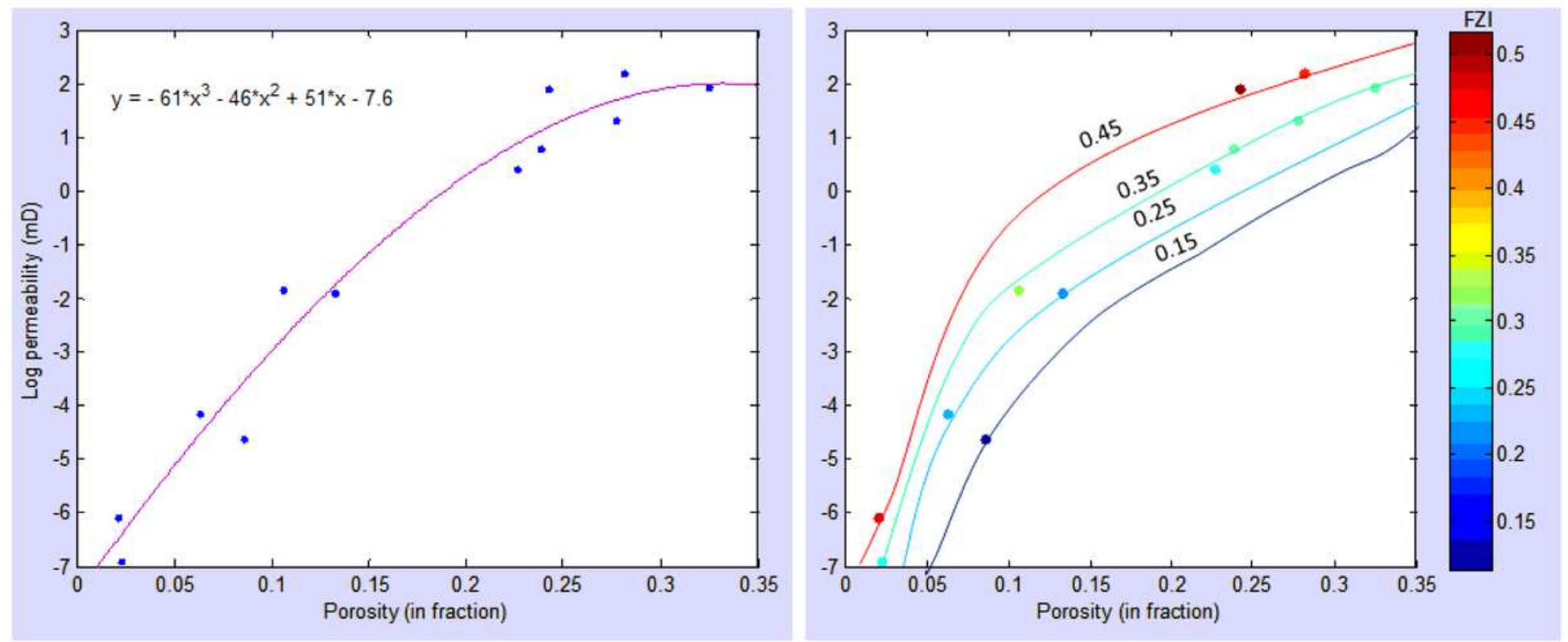

Figure 4 
Permeability based on the concept of Flow Zone Units (FZI). The permeabilityporosity distribution for well locations shown in Table 1 is plotted on the left. The computed flow zone indicators are shown on the right. The flow zone intervals are shown by different colors in the color bar.

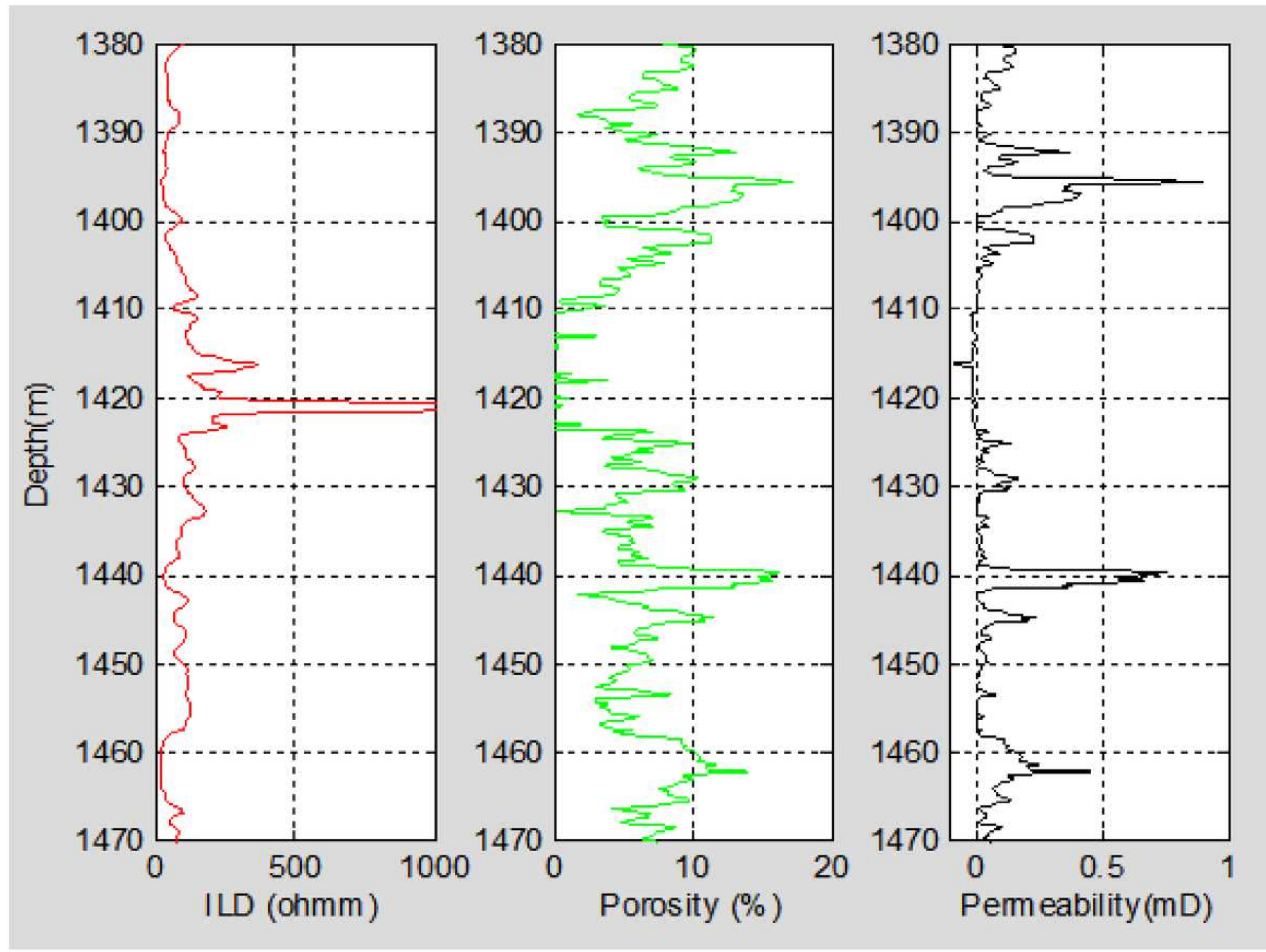

\section{Figure 5}

Predicted permeability changes at the reservoir scale using flow zone interval 0.35 . The derived permeability follows same trend as the porosity log that is characterized by significant changes in the red beds at 1400, 1440 and $1465 \mathrm{~m}$. Plotted alongside is the deep lateral induction (ILD) resistivity log. The high ILD reading is due to presence of diabase sills. 


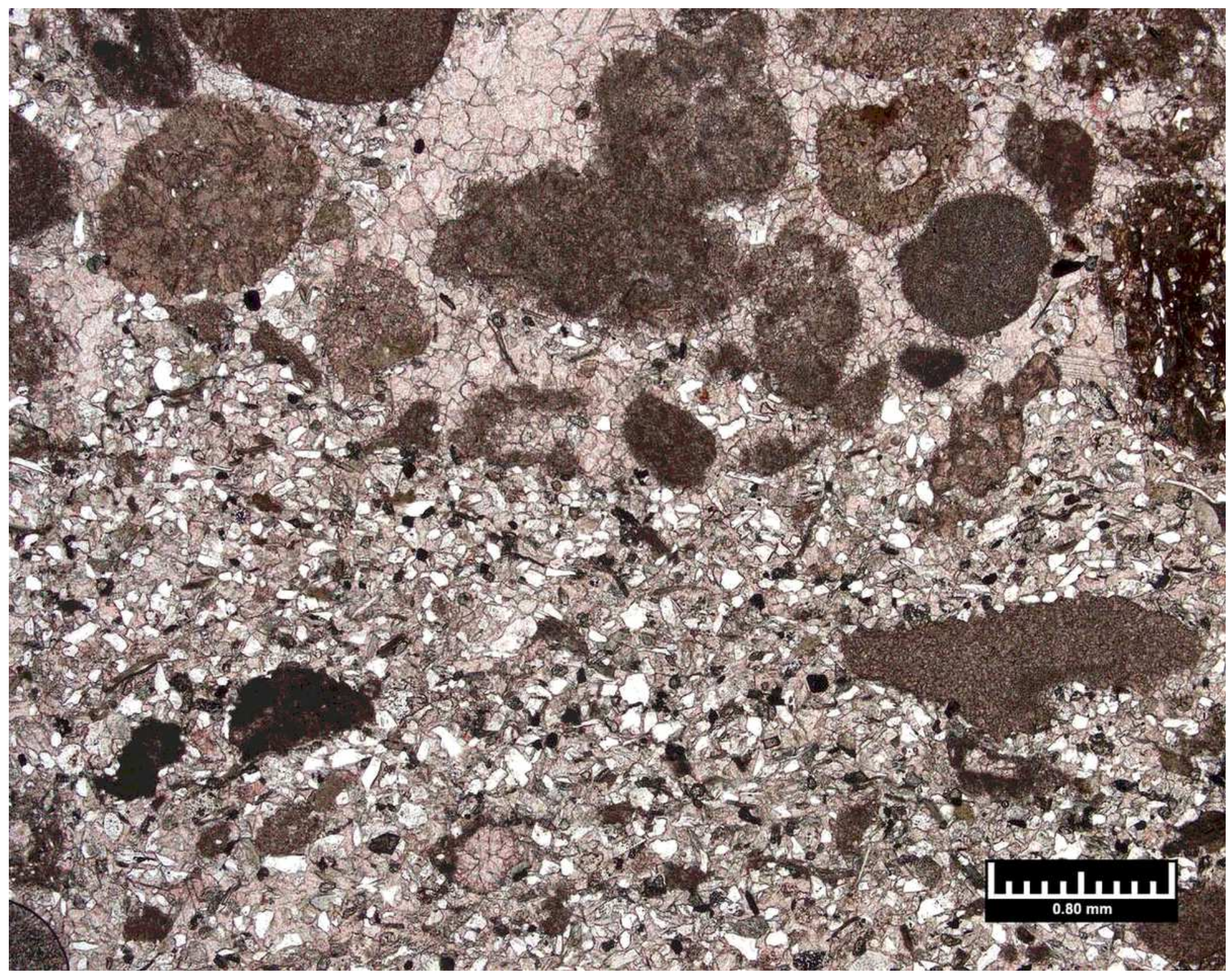

Figure 6

Photomicrograph of a thin section of a red bed at the Rizer \#1 Test Borehole at $1172.11 \mathrm{~m}$ and net confining stress $11.03 \mathrm{MPa}$ (Megapascal). It consists of very fine-grained sandstone and coarse-grained calcitic and mudstone clasts. Though well sorted, the presence of clasts and compaction are factors that reduce the permeability. The various colors are due to variations in mineralogical composition consisting of quartz and calcite, biotite, feldspar, and chlorite (after Weatherford Laboratories Report, 2014). 


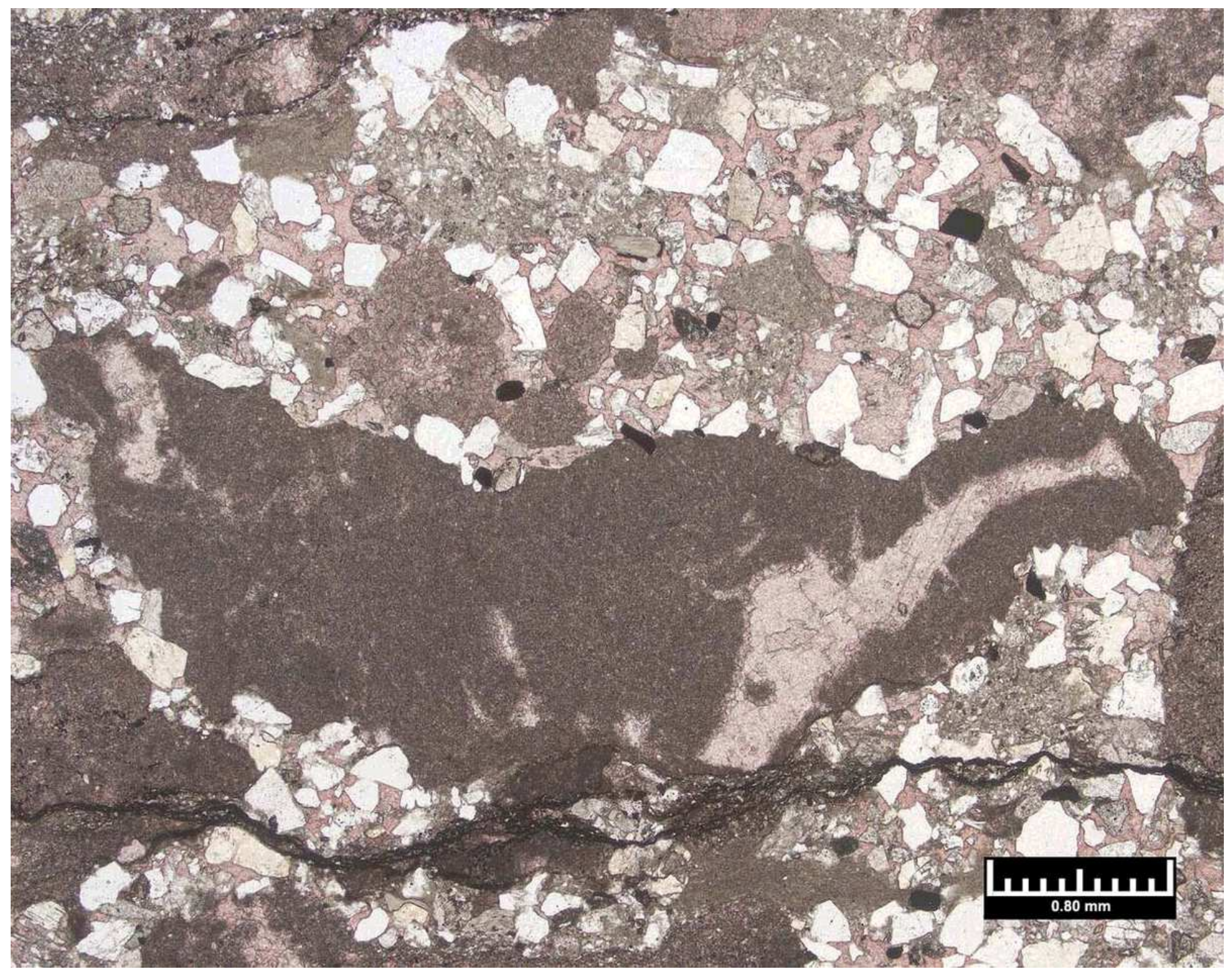

Figure 7

Photomicrograph of a thin section of a medium grained red bed at the Rizer \#1 Test Borehole at 1602.64 $\mathrm{m}$ and net confining stress $11.38 \mathrm{MPa}$. It is a poorly sorted, sandy clast conglomerate mixed with silt and clay. The dark color is due presence of claystone and silty claystone casts. The light red color is due to presence of calcite. Quart grains are common with minor amounts of potassium feldspar (after Weatherford Laboratories Report, 2014). 


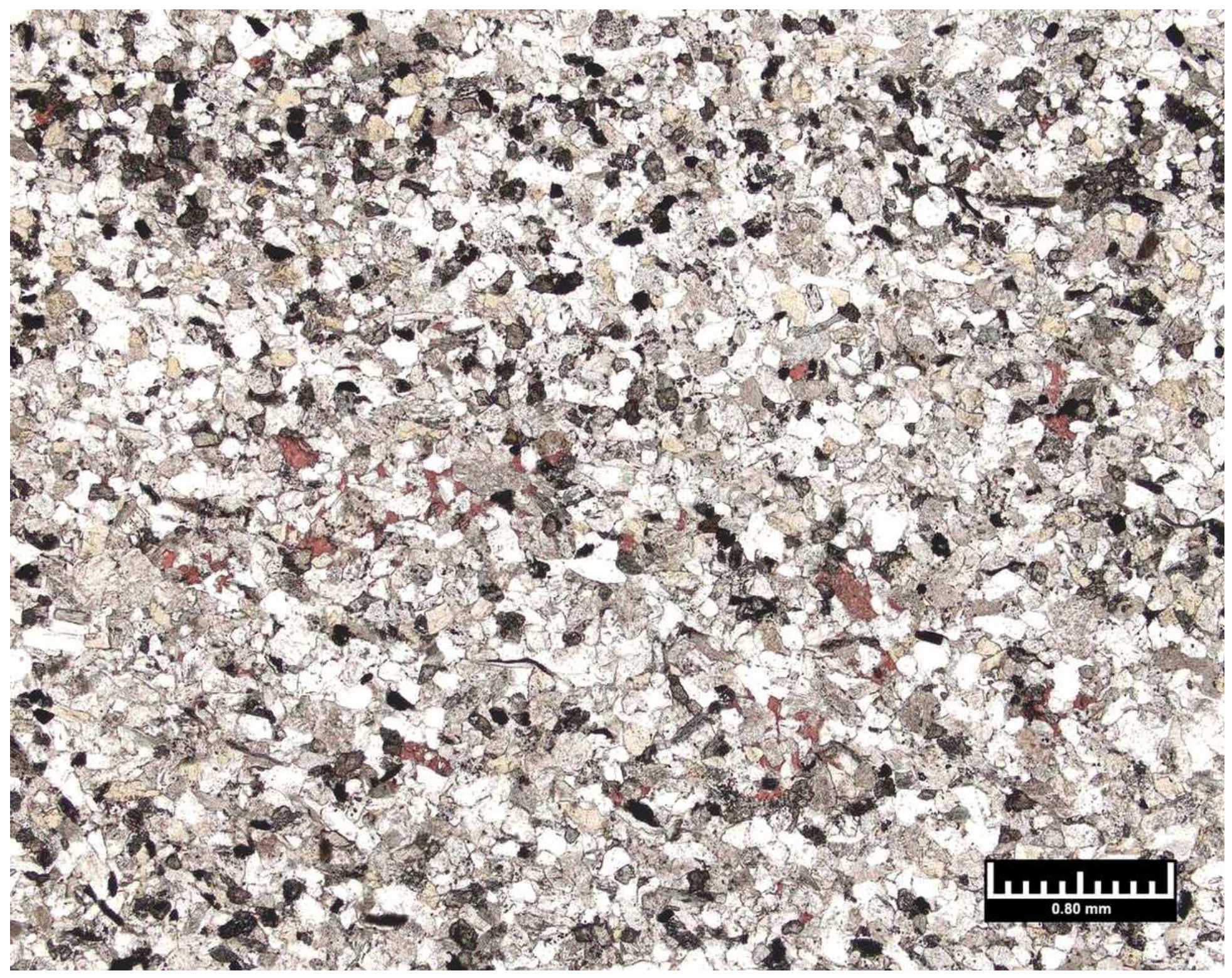

Figure 8

Photomicrograph of a thin section of a fined grained red bed at the Rizer \#1 Test Borehole at $1773.48 \mathrm{~m}$, and net confining stress $12.76 \mathrm{MPa}$. Though well sorted, it is highly compacted and cemented effectively reducing the pore size and pore connectivity responsible for permeability. Quartz and calcite (light red) are common (after Weatherford Laboratories Report, 2014). 


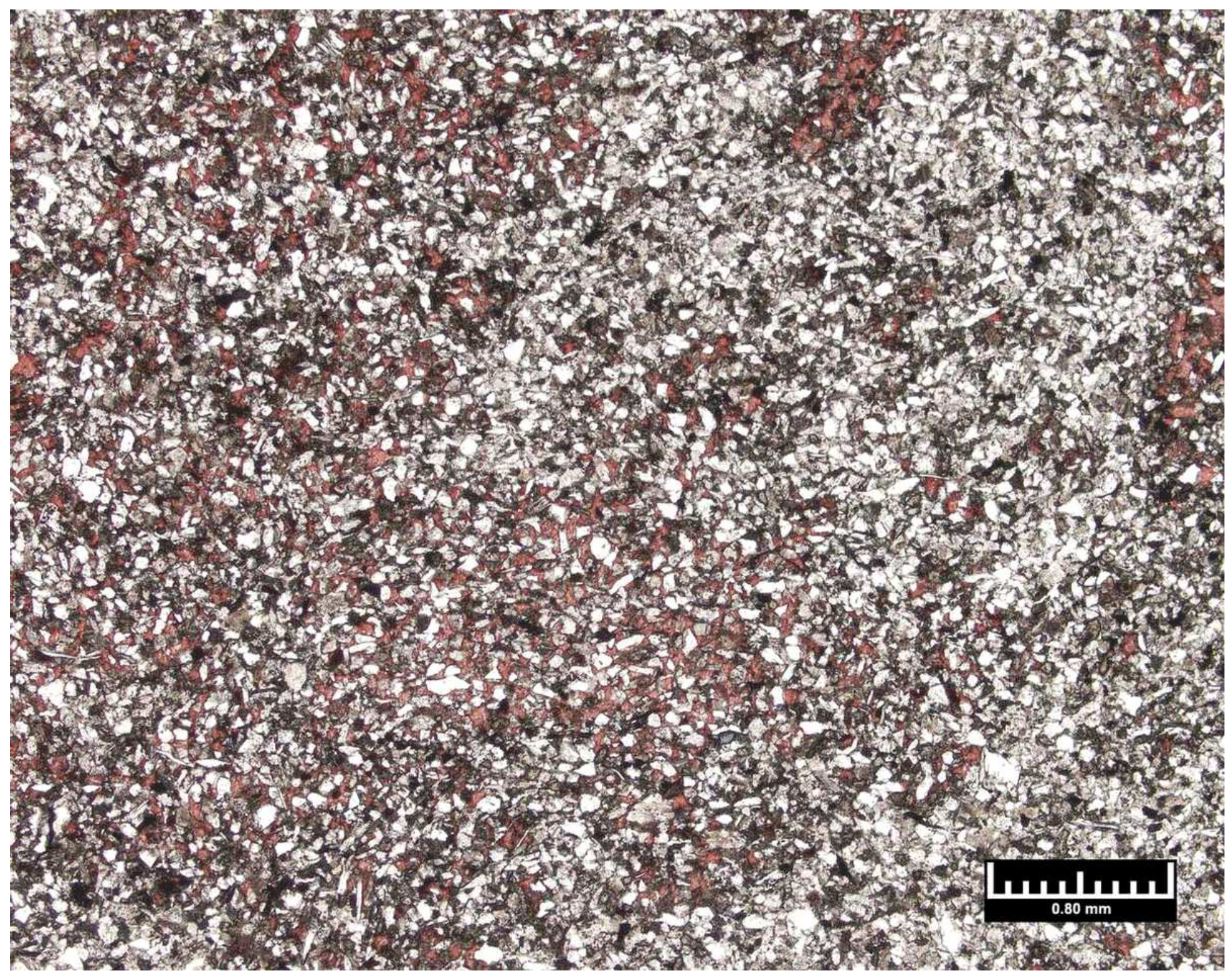

Figure 9

Photomicrograph of a thin section of a very fined grained red bed at the Rizer \#1 Test Borehole at $1862.33 \mathrm{~m}$, and net confining stress $13.10 \mathrm{MPa}$. It is well sorted but its lithified and compacted nature is not helpful to permeability. Changes in color are due to variations in mineralogy (after Weatherford Laboratories Report, 2014).

\section{Supplementary Files}

This is a list of supplementary files associated with this preprint. Click to download.

- Table.pdf 